\title{
Cancer Incidence and Distribution at a Tertiary Care Hospital in Somalia from 2017 to 2020: An Initial Report of I306 Cases
}

This article was published in the following Dove Press journal: Cancer Management and Research

\author{
Mehmet Tahtabasi' \\ Ismail Mohamud Abdullahi \\ Mustafa Kalayci $\mathbb{D D}^{3}$ \\ Ismail Gedi Ibrahim (D) \\ Sadettin $\operatorname{Er}\left(\mathbb{D}^{4}\right.$ \\ 'Department of Radiology, University of \\ Health Sciences- Somalia Turkey Recep \\ Tayyip Erdogan Education and Research \\ Hospital, Mogadishu, Somalia; \\ ${ }^{2}$ Department of Pathology, University of \\ Health Sciences- Somalia Turkey Recep \\ Tayyip Erdogan Education and Research \\ Hospital, Mogadishu, Somalia; \\ ${ }^{3}$ Department of Ophthalmology, \\ University of Health Sciences- Somalia \\ Turkey Recep Tayyip Erdogan Education \\ and Research Hospital, Mogadishu, \\ Somalia; ${ }^{4}$ Department of General \\ Surgery, University of Health Sciences- \\ Somalia Turkey Recep Tayyip Erdogan \\ Education and Research Hospital, \\ Mogadishu, Somalia
}

Correspondence: Mehmet Tahtabasi Mogadishu Somalia Turkey Recep Tayyip Erdogan Education and Research Hospital Tel +905076/59932

Email mehmet.tahtabasi@sbu.edu.tr
Purpose: To determine the type, frequency and distribution of all cancers in Somalia from 2017 to 2020.

Patients and Methods: This retrospective and descriptive study included the review of a total of 5238 pathology reports obtained from the medical records of the Somalia Turkey Recep Tayyip Erdogan Education and Research Hospital. Patient characteristics, lesion localization, and histopathology were recorded. Patients with an unconfirmed cancer diagnosis, borderline tumors, intraepithelial neoplasms and metastatic cancers were excluded from the study. The cases were classified according to gender, age, and organ involvement. Results: Of the 1306 patients included in the study, 50.9\% $(n=666)$ were female and $49.1 \%$ $(n=640)$ were male, and the mean age was $51.1 \pm 19.4$ years. Of the cases, $5.1 \%(n=67)$ were pediatric $(0-17$ years $)$ and $35.8 \%(n=468)$ were in the $18-50$ years range. The most common cancer was esophageal cancer (EC) for the overall data $(n=284 ; 21.7 \%)$ and in both genders. EC peaked in the fifth decade, and the most common histological type was squamous cell carcinoma $(n=256 ; 91.1 \%)$. Liver cancer was the second most common cancer overall $(n=99$; $7.6 \%)$ and in men $(n=67 ; 10.5 \%)$. Cervical cancer was the second most common cancer among women $(n=88 ; 13.3 \%)$ and ranked fourth in terms of overall incidence $(n=88 ; 6.7 \%)$. Breast cancer was the third most common overall $(n=95 ; 7.3 \%)$ and in women $(n=87 ; 13.1 \%)$.

Conclusion: This study shows that in Somalia, EC is the most common cancer in both genders. These high rates in Somalia suggest that environmental factors and dietary habits may have an effect. To reduce the incidence of EC and prevent its development, the population of Somalia should be educated and effective planning should be undertaken.

Keywords: Somalia, incidence rate, cancer, esophageal cancer, epidemiology

\section{Introduction}

Cancer is an important cause of mortality in both economically underdeveloped and highly developed countries. Due to the increase in population and aging, cancer is expected to increase throughout the world, but especially in underdeveloped countries in which $82 \%$ of the global population lives. ${ }^{1}$ According to the 2015 estimates of the World Health Organization (WHO), cancer is the first or second cause of mortality in 91 of 172 countries before the age of 70 years, and the third or fourth cause of mortality in $22 . .^{2,3}$ The ongoing global demographic and epidemiologic transitions mean an increasing cancer burden, especially in low and middle-income countries for the following decades. It is estimated that the global cancer burden caused 14.1 million new cases and 8.2 million deaths in 2012, which increased to http:ldd 
18.1 million new cases and 9.6 million deaths in 2018 . Globally, one in five men and one in six women develop cancer in their lifetime, while one in eight men and one in 11 women die of this disease. ${ }^{2-4}$ In Africa, it is estimated that there were $1,055,172$ new cancer cases $(5.8 \%$ of the global total) and 693,487 cancer deaths $(7.3 \%$ of the global total) in 2018. The world has been divided into 20 regions to estimate cancer incidence and mortality rates. Somalia is included in the East African region. It is evaluated that approximately one-third of cancer cases in Africa occurs in the East Africa region. ${ }^{3}$

Since there is no national cancer registry system in Somalia, the population-based cancer incidence is not known. Although Baş et $\mathrm{al}^{5}$ conducted the first study in 2017 to evaluate the cancer incidence in Somalia, especially in the capital Mogadishu and its surroundings, due to the limited number of patients, the results were not sufficient to reflect the real situation for the whole population. Therefore, the current study can be considered as the first comprehensive retrospective study on cancer incidence in the region. Furthermore, previous cancer incidence studies related to the population in Somalia were conducted with immigrants living in the United States of America (USA), and most only focused on women and on a single type of cancer; eg, cervical or breast cancer. Thus, a definitive conclusion has not yet been made regarding the incidence of all cancers in the region. ${ }^{6}$ The current study aimed to determine both the cancer type and distribution of cancers by age and gender in patients diagnosed in Somalia Turkey Recep Tayyip Erdogan Education and Research Hospital (STRTEH) over a threeyear period from January 1, 2017 to December 31, 2019.

\section{Materials and Methods}

\section{Study Population and Data Collection}

STRTEH, founded in the capital Mogadishu in 2015, is the most equipped referral and consultant hospital in the region in terms of health equipment. The hospital provides tertiary health services and is equipped for all types of surgical operations and imaging procedures, including ultrasound (US), computed tomography (CT), and magnetic resonance imaging (MRI), as well as imaging-guided biopsy procedures. Surgical specimens or biopsy materials are transferred to the pathology laboratory for analysis, and the demographic characteristics of all cases (age, gender, and place of residence), sample/material collection area, sampling method (eg, needle aspiration and incisional or excisional biopsy), and histopathological characteristics are recorded in detail in the electronic medical system. For this study, a total of 5238 pathology reports were retrospectively obtained from the electronic records of STRTEH for a three-year period from January 1, 2017 to December 31, 2019. Patients with an unconfirmed cancer diagnosis or incomplete medical records, those with borderline tumors or intraepithelial neoplasia, those that did not reside in Somalia or had an unspecified place of residence, and those with metastatic cancer with a known primary source were not included in the study.

In the presence of more than one biopsy taken from the same patient's organ, the most representative sample was used. If there were biopsies from different organs of one patient, they were separately included in the evaluation. As a result, a total of 1306 patients diagnosed with cancer either histologically or cytologically were included in this study. The cases were classified according to gender, age and organ/system involvement, and the 10 most common types of cancer were categorized according to age and gender distribution. The most common cancers were histopathologically divided into subgroups. The local ethics committee approval was obtained for this retrospective and descriptive study (13.05.2020- MSTH/3785).

\section{Statistical Analyses}

All analyses were performed using SPSS v. 22.0 (IBM SPSS Statistics Version 22.0. Armonk, NY: IBM Corp.) software. Age and gender were expressed as mean \pm standard deviation and numbers and percentages. Categorical variables were expressed as numbers and percentages.

\section{Results}

\section{Age and Gender Distribution}

Of the 1306 patients diagnosed with cancer between 2017 and 2020, 50.9\% $(\mathrm{n}=666)$ were female and 49.1\% $(\mathrm{n}=$ 640) were male, and the mean age of the patients was 51.1 \pm 19.4 years. Of the cases, $5.1 \%(\mathrm{n}=67)$ were pediatric $(0-17$ years $), 35.8 \%(\mathrm{n}=468)$ were in the $18-50$ years range, and $59.1 \%(\mathrm{n}=771)$ were over 50 . The mean age at the time of diagnosis was $53.1 \pm 21.1$ years for men and $49.3 \pm 17.5$ years for women.

\section{Cancer Types by Age Group}

Organ/system, gender and age distributions of all cancers are shown in Table 1, and the distribution of the most 
common 10 cancers for both genders are given in Figures 1 and 2. In Figure 2, the most common cancers are compared with age-standardized rates (ASRs) of regions with low/medium human development indexes. The overall cancer incidence in both women and men was mostly observed to peak in the fifth decade, followed by the sixth decade (Figure 3).

Esophageal cancer (EC) was the most common cancer overall $(n=284 ; 21.7 \%)$ and in both genders. The ratio of men $(\mathrm{n}=145 ; 22.7 \%)$ to women $(\mathrm{n}=139 ; 20.9 \%)$ was $1: 1$ for this cancer. It was determined that EC was seen every decade during adulthood, peaking in the fifth and sixth decades. The mean age of these patients was $56.5 \pm 14.4$ years (Figure 4). Considering the histopathological subtypes of EC, the most common was squamous cell carcinoma $(\mathrm{SCC}) \quad(\mathrm{n}=256 ; 91.1 \%)$, followed by adenocarcinoma $(\mathrm{n}=11 ; 3.9 \%)$ and other types of cancer (undifferentiated and neuroendocrine carcinoma, and sarcoma). Most of the patients with EC presented with advanced symptoms, such as progressive dysphagia and weight loss, as well as lymph node (supraclavicular, cervical or mediastinal) or distant organ (liver and lung) metastasis. For the diagnosis, esophagoscopy was performed using a fiberoptic flexible endoscope. Generally, a biopsy was performed with forceps for a histopathological diagnosis, and head and neck lymphadenopathies were examined with a fine-needle aspiration biopsy (FNAB). Thoracoabdominal CT was used to evaluate the stage of the disease. When the $\mathrm{CT}$ reports were examined, it was seen that almost all of the patients were in an inoperable advanced stage (T3 and T4). A palliative intraluminal stent or gastrostomy tube was placed in these patients. Patients that received palliative treatment died in a short time since they were not able to undergo chemoradiotherapy or they were transferred to other countries. Liver cancer constituted $7.6 \%(n=99)$ of all cancers for the overall data while it was the second most common cancer in men $(\mathrm{n}=67 ; 10.5 \%)$ and ranked sixth among women $(\mathrm{n}=32 ; 4.8 \%)$. Only 19.2\% $(\mathrm{n}=19)$ of liver cancer cases had hepatitis B virus (HBV) $(n=17)$ and hepatitis $\mathrm{C}$ virus $(\mathrm{HCV})(\mathrm{n}=2)$ positivity. Cervix uteri cancer was the second most common cancer among women $(\mathrm{n}=88 ; 13.3 \%)$ and had the fourth most common overall incidence $(6.7 \% ; n=88)$. Breast cancer, which constituted $7.3 \%$ (95) of all cancers, ranked third in terms of incidence for both the whole sample and women $(\mathrm{n}=87 ; 13.1 \%)$. The distribution of breast cancer by subtypes and age is given in Figure 5.
Tables 2 and 3 present the most common types of cancer in other African countries compared to the data obtained from the current study. In addition, the types and incidence of cancer in pediatric cases are shown in Table 4 and Figure 6.

\section{Discussion}

This first comprehensive study in Somalia describes the distribution of 1306 cancer cases by age and gender observed in the region from 2017 to 2020. This reveals important epidemiological data for the conduct of clinical practices and scientific activities in the region and in cancer control planning. Unfortunately, the true incidence of cancer is not yet known in Somalia as in all other Sub-Saharan Africa (SSA) countries with a low income. ${ }^{7}$ Cancer incidence in these countries is often based on hospital-based local cancer registries located in the capital or urban areas. Population-based cancer registries are the gold standard for a comprehensive understanding of the cancer burden. ${ }^{8}$ In developing population-based cancer registries, multiple steps, involving the definition of the geographic area and population to be covered, having official population estimates for the targeted group, having access to individual medical records and other resource documents (death reporting forms and chemotherapy records), and establishing a continuous communication and information network with local information sources to maintain the data flow are required. Hospital-based and regional cancer registries that produce high-quality data can also be an important and intermediate source for achieving this goal. ${ }^{9}$ Since the global cancer statistics estimates cannot obtain local data from 32 countries, including Somalia, they indicate the cancer incidence estimates according to the average rates of neighboring countries. Cancer incidence estimates in Somalia are based on the average of Ethiopia and Kenya as there is no local data. ${ }^{10}$ Therefore, global cancer statistics data are different from the results of our study. Due to the lack of a national cancer registry system in Somalia, the exact results are not known like other countries. However, since STRTEH is the most equipped referral hospital in Somalia in terms of cancer and other diseases, the current study contains the most reliable data reflecting the true incidence. Our data belonged to hospital-based cancer registries in STRTEH, and the results related to the most common cancer types are discussed below. 
Table I Distribution of Cancer Cases in Somalia According to Gender and Affected Organ from January 0I, 20I7 to December 3I, 2019

\begin{tabular}{|c|c|c|c|c|c|}
\hline & Location & Total n (\%) & Men n (\%) & Women n (\%) & Age (Years) Mean \pm SD \\
\hline I & Esophagus & $284(21.7)$ & 145 (22.7) & $139(20.9)$ & $56.5 \pm 14.4$ \\
\hline 2 & Liver & $99(7.6)$ & $67(10.5)$ & $32(4.8)$ & $59.6 \pm 19.1$ \\
\hline 3 & Breast & $95(7.3)$ & $8(1.3)$ & $87(13.1)$ & $44.7 \pm 13.6$ \\
\hline 4 & Cervix uteri & $88(6.7)$ & $0(0)$ & $88(13.3)$ & $51.8 \pm 15.1$ \\
\hline 5 & Colorectal & $68(5.2)$ & $45(7)$ & $23(3.5)$ & $40.6 \pm 20.7$ \\
\hline 6 & Thyroid & $65(5.0)$ & $25(3.9)$ & $40(6.0)$ & $39.5 \pm 13.1$ \\
\hline 7 & Soft tissue & $58(4.4)$ & $31(4.8)$ & $27(4.1)$ & $41.1 \pm 21.7$ \\
\hline 8 & Prostate & $56(4.3)$ & $56(8.8)$ & $0(0)$ & $73.8 \pm 11.1$ \\
\hline 9 & Lung & $56(4.3)$ & $34(5.3)$ & $22(3.3)$ & $59.9 \pm 15.1$ \\
\hline 10 & Bladder & $54(4.1)$ & $44(6.9)$ & $10(1.5)$ & $58.1 \pm 17.2$ \\
\hline 11 & Lymphoma & $44(3.4)$ & $34(5.3)$ & $10(1.5)$ & $38.6 \pm 23.8$ \\
\hline 12 & Corpus uteri & $33(2.5)$ & $0(0)$ & $33(5.0)$ & $55.3 \pm 13.2$ \\
\hline 13 & Nasopharynx & $34(2.6)$ & $19(3.0)$ & $15(2.3)$ & $38.7 \pm 23.1$ \\
\hline 14 & Skin & $37(2.8)$ & $22(3.4)$ & $15(2.3)$ & $52.4 \pm 16.2$ \\
\hline 15 & Tongue & $30(2.3)$ & $20(3.1)$ & $10(1.5)$ & $47.7 \pm 20.2$ \\
\hline 16 & Brain & $21(1.6)$ & $10(1.6)$ & II (I.7) & $44.3 \pm 24.1$ \\
\hline 17 & Ovary & $20(1.5)$ & $0(0)$ & $20(3.0)$ & $45.8 \pm 15.1$ \\
\hline 18 & Salivary & $25(1.9)$ & $14(2.2)$ & $\mathrm{II}(1.7)$ & $36.8 \pm 17.9$ \\
\hline 19 & Pancreas & $15(1.1)$ & $5(0.8)$ & $10(1.5)$ & $61.4 \pm 17.4$ \\
\hline 20 & Bone & $12(0.9)$ & $7(1.1)$ & $5(0.8)$ & $45.4 \pm 20.5$ \\
\hline 21 & Stomach & $13(1.0)$ & $6(0.9)$ & $7(1.1)$ & $56.9 \pm 16.0$ \\
\hline 22 & Peritoneal fluid & $10(0.8)$ & $6(0.9)$ & $4(0.6)$ & $47.7 \pm 17.7$ \\
\hline 23 & Nasal cavity & $10(0.8)$ & $7(I . I)$ & $3(0.5)$ & $40.9 \pm 14.1$ \\
\hline 24 & Pleural fluid & $13(1.0)$ & $6(0.9)$ & $7(1.1)$ & $48.1 \pm 17.4$ \\
\hline 25 & Lip, oral cavity & $16(1.2)$ & $10(1.6)$ & $6(0.9)$ & $59.5 \pm 16.8$ \\
\hline 27 & Testis & $7(0.5)$ & $7(1.1)$ & $0(0)$ & $56.8 \pm 22.3$ \\
\hline 28 & Kidney & $6(0.5)$ & $3(0.5)$ & $3(0.5)$ & $47.3 \pm 26.3$ \\
\hline 29 & Wilms & $9(0.7)$ & $5(0.8)$ & $4(0.6)$ & $3.9 \pm 3.3$ \\
\hline 30 & Gallbladder & $\mathrm{I}(0.1)$ & $0(0)$ & I (0.2) & 66 \\
\hline 31 & Larynx & $13(1.0)$ & $7(1.1)$ & $6(0.9)$ & $56.5 \pm 14.7$ \\
\hline 32 & Hypopharynx & $7(0.5)$ & $\mathrm{I}(0.2)$ & $6(0.9)$ & $43.1 \pm 13.1$ \\
\hline 33 & Appendix & $\mathrm{I}(0.1)$ & $0(0)$ & I (0.2) & 27 \\
\hline 34 & Small intestine & $4(0.3)$ & $2(0.3)$ & $2(0.3)$ & $40.2 \pm 19.7$ \\
\hline 35 & Eye & $2(0.2)$ & $2(0.3)$ & $0(0)$ & $3 \pm 1.4$ \\
\hline Total & & $1306(100)$ & $640(100)$ & $666(100)$ & $51.1 \pm 19.4$ \\
\hline
\end{tabular}

\section{Esophageal Cancer (EC)}

According to the 2018 data of global cancer statistics, lung cancer $(11.6 \% ; \mathrm{n}=2,093,876)$ is the most common type of cancer, followed by breast $(11.6 \% ; n=2,088,849)$, colorectal $(10.2 \%)$ and prostate $(7.1 \%)$ cancers. According to the gender analysis, the order of cancers by incidence is lung (14.5\%), prostate (13.5\%) and colorectal (10.9\%) for men, and breast $(24.2 \%)$, colorectal $(9.2 \%)$ and lung (8.4\%) for women. ${ }^{11}$ In contrast, in the current study, EC was found to be the most common type of cancer in Somalia for the overall data and for both genders. It was detected equally in both genders (male/female ratio: 1).
Although EC was seen in all decades, it was mostly observed to peak in the fifth and sixth decades. GLOBOCAN 2018 data show that 5\% $(\mathrm{n}=28,494 /$ $572,034)$ of EC cases worldwide are seen in Africa. In addition, although the global mortality rate is $88.9 \%$, this rate has been reported to be higher in Africa $(97.2 \%$; $\mathrm{n}=$ $27,703 / 28,494)$. In the same study, it is stated that EC is two to three times more common in men worldwide. $\mathrm{EC}$ is 2 to 8 times more common in men than in women in most areas of the world. However, the EC incidence was detected equally in both genders (male/female ratio: 1) in this study, which is an important finding. In a recent 


\section{New Cancer Cases in Somalia in 2017-2020}

\begin{tabular}{llll} 
& \multicolumn{2}{c}{ Men } \\
Esophagus & $22.7 \%$ \\
Liver & $10.5 \%$ \\
Prostate & $8.8 \%$ \\
Colorectal & $7 \%$ \\
Bladder & $6.9 \%$ \\
Lymphoma & $5.5 \%$ \\
Lung & $5.3 \%$ \\
Soft tissue & $4.8 \%$ \\
Thyroid & $3.9 \%$ \\
Skin & $3.4 \%$ \\
All other sites & $21.2 \%$
\end{tabular}

Figure I The most common 10 cancers seen in both genders in Somalia.

epidemiological study, Pan et $\mathrm{al}^{34}$ found that EC is only up to about 1.5 -fold more common in men than in women in a rural area, and alcohol/tobacco use play only a minor role, whereas some other factors that influence both sexes equally may take the main responsibility, such as environmental and dietary factors. Therefore, the areas where have high EC incidence may have something in common. While EC is the leading cause of cancer mortality in men in Kenya, it has been shown to have the highest global incidence in both men and women in Malawi. ${ }^{3,12}$ These patients may remain clinically asymptomatic for a long time. If the disease progresses, it can lead to complaints, such as weight loss and dysphagia. All the patients in the current study presented with progressive dysphagia or weight loss in the advanced stage of the disease. Unfortunately, due to the lack of endoscopic US (EUS) and positron emission tomography (PET) in Somalia, CT was used for staging. Although at the time of presentation, almost all patients were at advanced stage; ie, T3 (invasion of adventitia) or T4 (invasion of adjacent structures), chemoradiation treatment could not be applied to these patients due to the absence of an oncology clinic. Furthermore, since oncological treatment costs are very high, only a small proportion of patients were able to travel to Turkey for this treatment. All these factors negatively affected the reliability of our data concerning the mortality rates. Tables 2 and 3 summarize the EC incidence of other African countries.

SCC is the dominant histological type for EC in East Africa. Tobacco and alcohol use are shown as risk factors for SCC in developed countries. However, despite the increasing westernization trend, tobacco use remains very low in East Africa, as well as among the African-American population in the USA. ${ }^{13}$ In a previous study, it was reported that tobacco use ranged from $9.2 \%$ to $23.9 \%$ among African men and $0.4 \%$ to $3 \%$ among African women. ${ }^{14}$ However, although multiple factors have been implicated in the EC etiology, including environmental and dietary factors, mineral or nutritional deficiencies, being deprived of the protective effect of fresh vegetables and fruits, and dietary contamination or viral infections, they require further investigation. ${ }^{14}$ In addition, HIV/AIDS continues to be an important comorbidity in East Africa, with some studies showing that the incidence of both SCC and adenocarcinoma increase in cases with AIDS. ${ }^{15}$ However, in a study conducted in Uganda, no increase was shown in the incidence of EC in people with HIV/AIDS. ${ }^{16}$ Other researchers attempting to link AIDS cases in East Africa to HIV/AIDS 

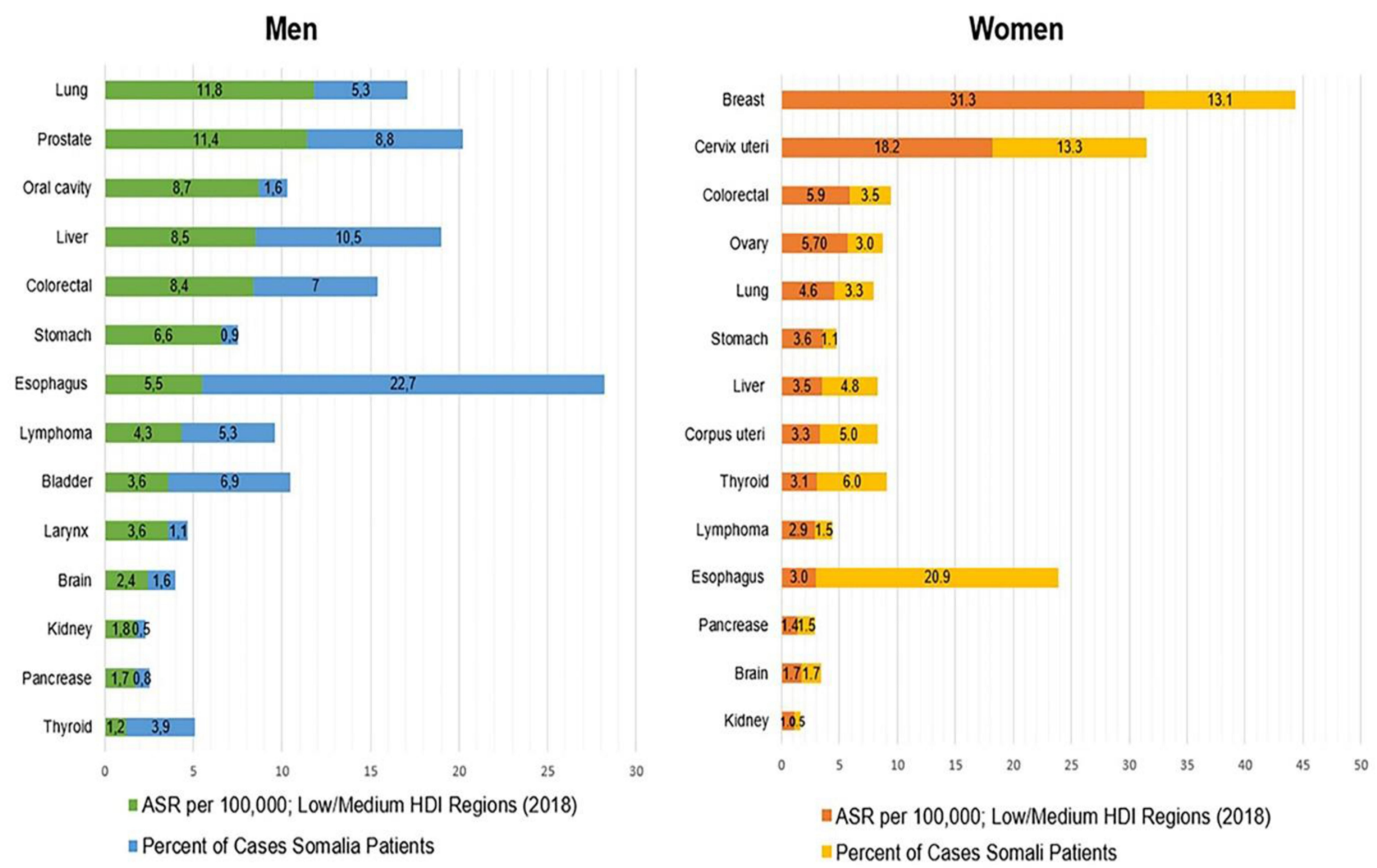

Figure 2 Bar charts of incidence and mortality age-standardized rates (ASR) in low/medium human development index (HDI) regions versus Somalia among men and women. Source: GLOBOCAN 2018. ${ }^{3}$

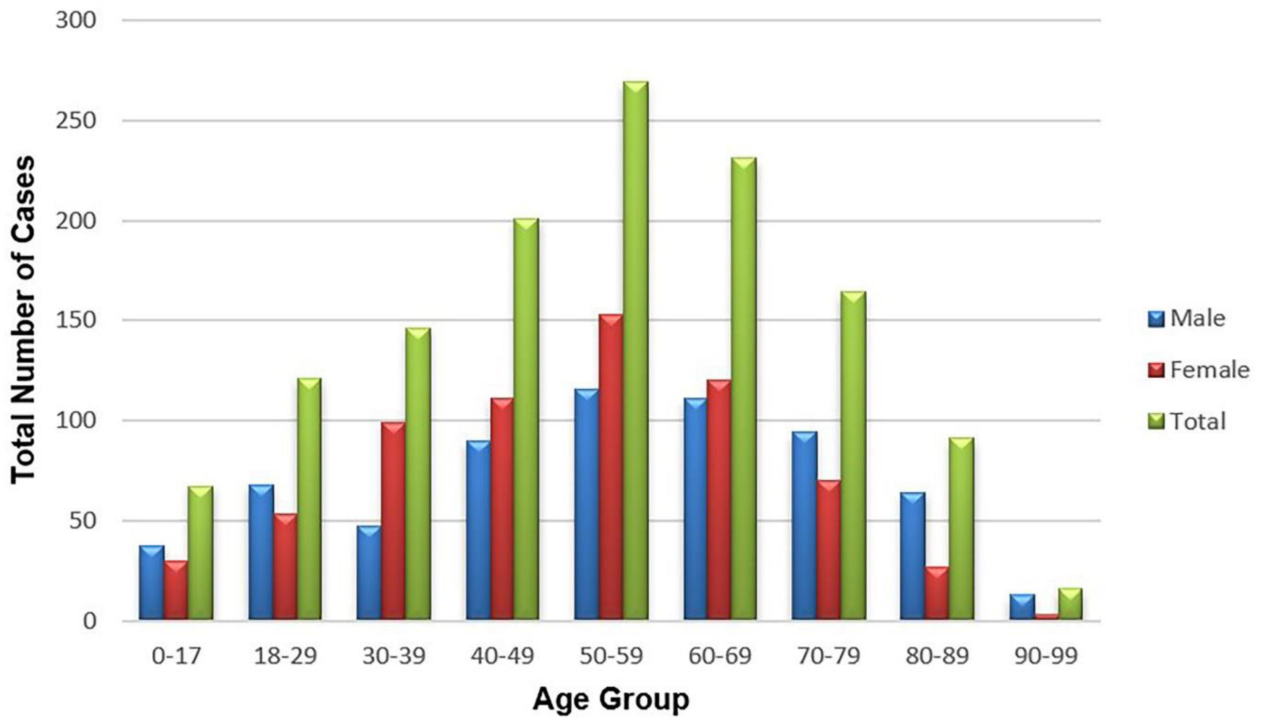

Figure 3 Frequency of cancer in Somalia patients stratified by age and gender.

also reported conflicting results. ${ }^{14}$ Similarly, more comprehensive studies are needed to determine whether infections, such as HIV and human papilloma virus (HPV) increases the incidence of EC. The histological analysis undertaken in the current study revealed that $91.1 \%(\mathrm{n}=256)$ of the cases had SCC. The production, consumption and sale of alcohol are prohibited in Somalia for religious reasons. The relatively low use of tobacco brings other factors to the fore for the 


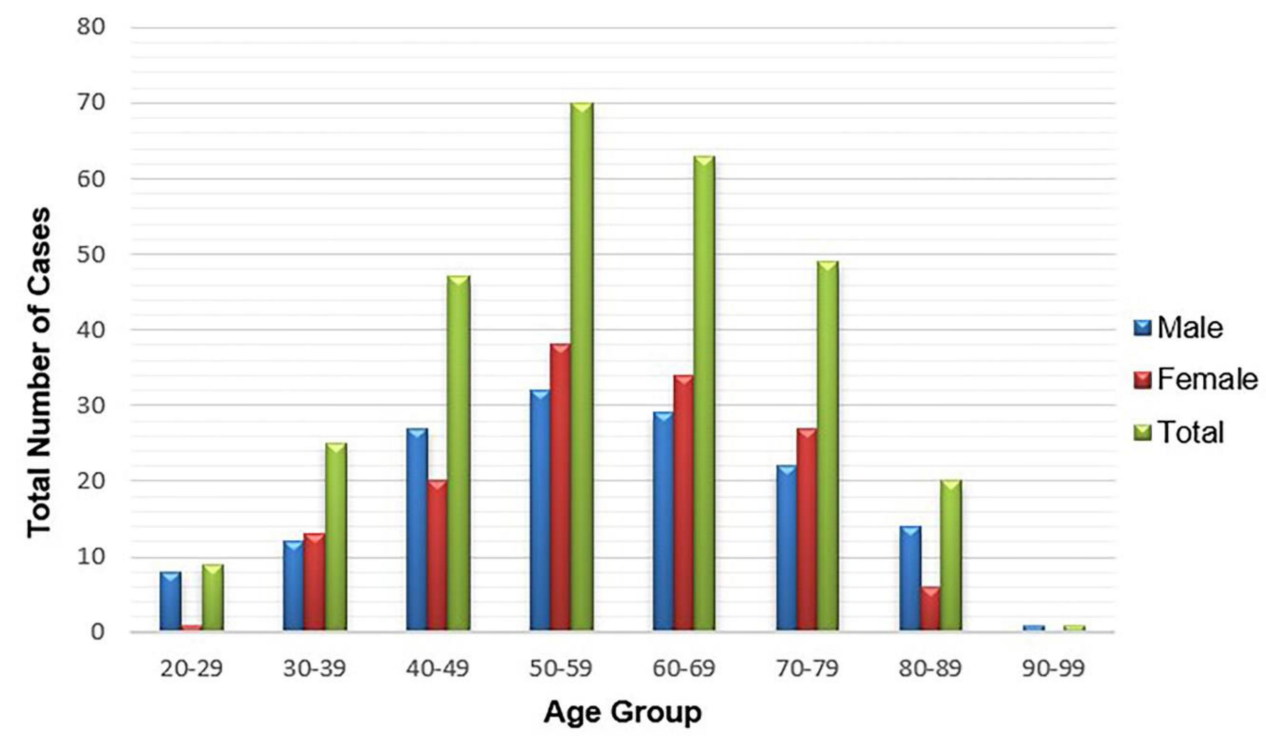

Figure 4 Frequency of esophageal cancer in Somalia patients stratified by age and gender.

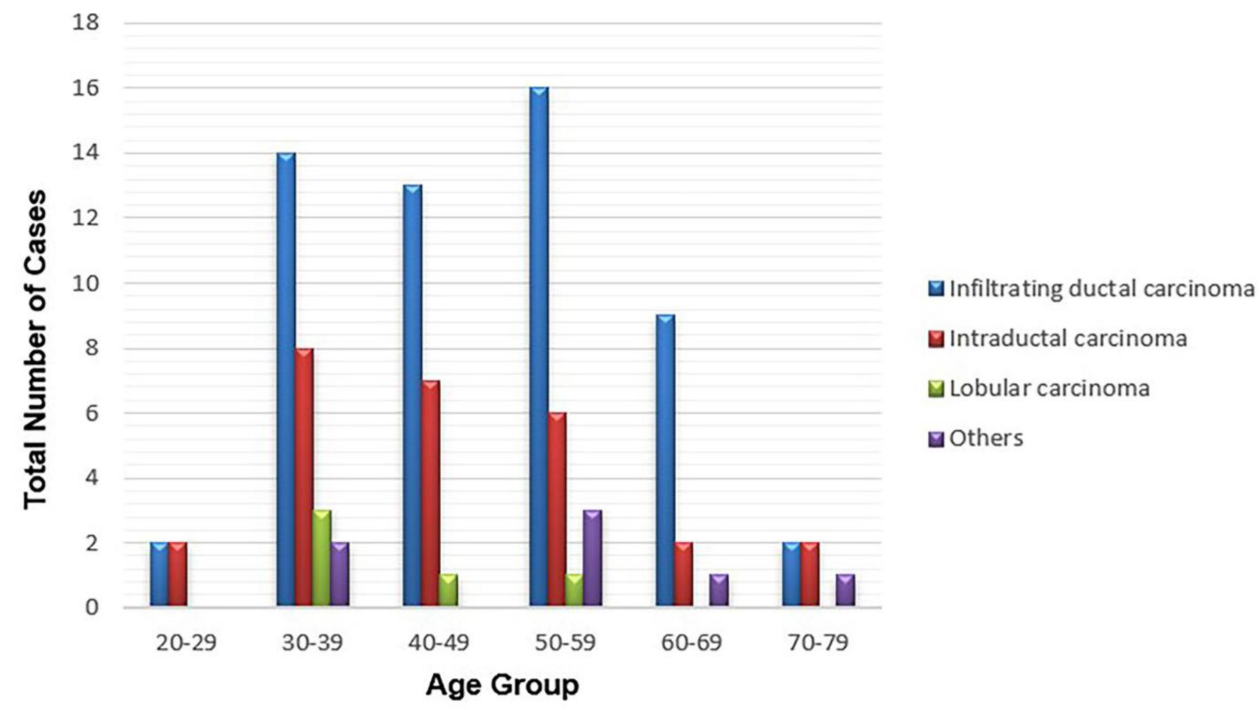

Figure 5 Frequency of breast cancer patients according to tumor type by age.

etiology of the disease. In this region, there is an excessive consumption of extremely hot tea and rice. ${ }^{17,18}$ In addition, another factor that should be questioned is the frequent use of the plant called qat (chat or khat; Catha edulis Forsskal). Chewed in the mouth, this herb is rich in alkaloids, does not contain nicotine, but has amphetamine-like effects, leading to a psychoactive effect. It is estimated that millions of people chew this plant in their daily lives in the Arabian Peninsula and various countries of South and East Africa. It is known that the highest-quality qat production is undertaken in Ethiopia, a neighbor of Somalia, and this plant is widely used in the surrounding regions, including Somalia.
A limited number of studies have suggested an association between upper gastrointestinal tract disorders (such as esophagitis, gastritis, and gastroesophageal reflux) and qat. However, well-designed analytical epidemiological studies have not yet been performed to provide evidence that the use of qat is a risk factor in the EC etiology. It is not easy to determine the relationship between qat and cancer in Somalia due to the fear of social exclusion of those who chew qat. ${ }^{19}$ In central Asian countries, especially in Japan, guidelines recommend mammography screening for breast cancer, pap smear test for cervical cancer, and endoscopic screening for stomach cancer for cancer control. ${ }^{20-22}$ In this 


\begin{tabular}{|c|c|c|c|c|c|c|c|c|c|c|}
\hline 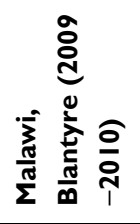 & 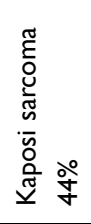 & 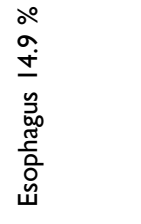 & 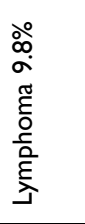 & 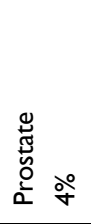 & 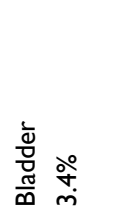 & 㐫 ஓे & 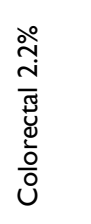 & 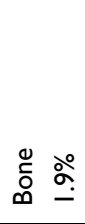 & 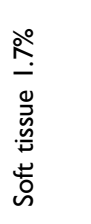 & 絯 \\
\hline 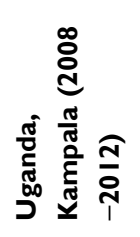 & 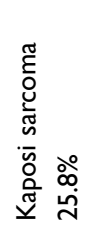 & 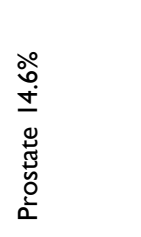 & 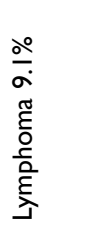 & 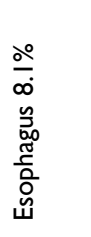 & 彥 爷 & $\stackrel{\circ}{\stackrel{\Delta}{4}} \frac{\circ}{m}$ & 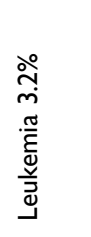 & 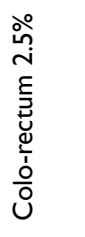 & 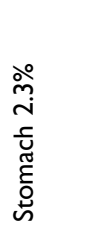 & 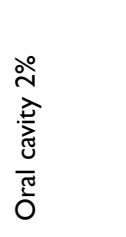 \\
\hline 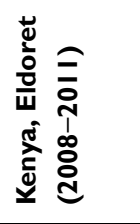 & 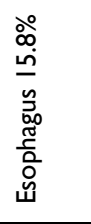 & 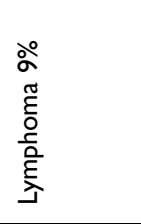 & 苞 & 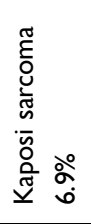 & 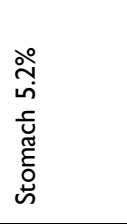 & 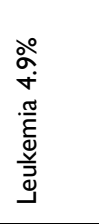 & 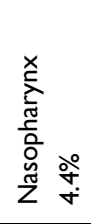 & 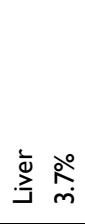 & 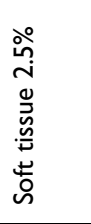 & 气ั \\
\hline 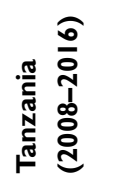 & 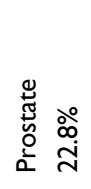 & 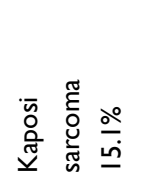 & 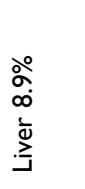 & 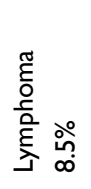 & 紊 & 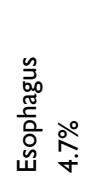 & $\begin{array}{l}\frac{\circ}{\grave{+}} \\
\frac{\grave{v}}{\bar{g}} \\
\frac{\mathrm{d}}{\omega}\end{array}$ & 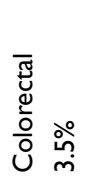 & 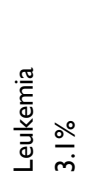 & 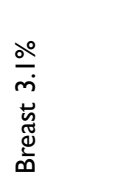 \\
\hline 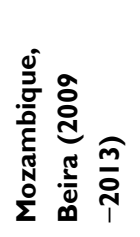 & 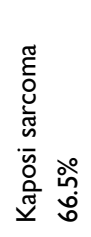 & 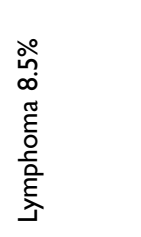 & 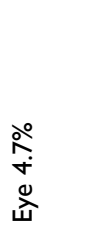 & 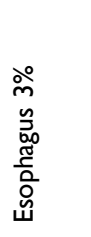 & 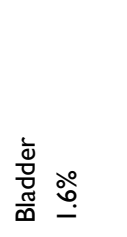 & 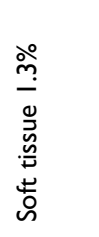 & 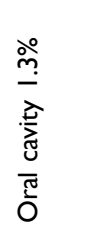 & 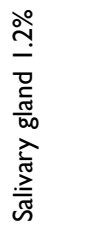 & 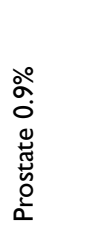 & 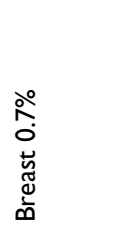 \\
\hline 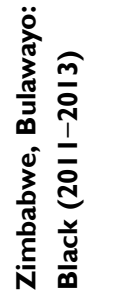 & 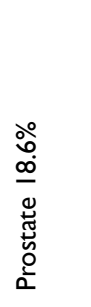 & 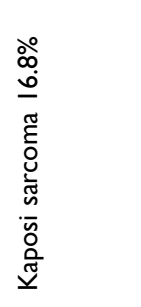 & 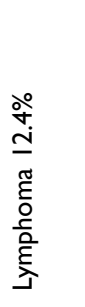 & 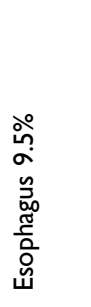 & $\begin{array}{l}\frac{\circ}{0} \\
\stackrel{0}{\bar{\nu}} \\
\stackrel{\Xi}{3}\end{array}$ & 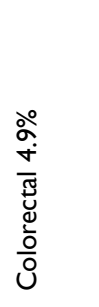 & 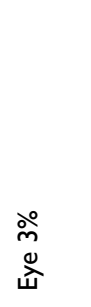 & 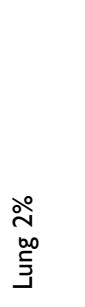 & 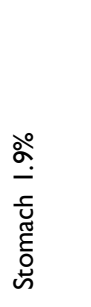 & 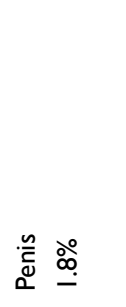 \\
\hline 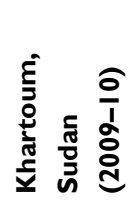 & 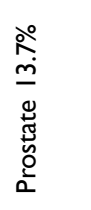 & 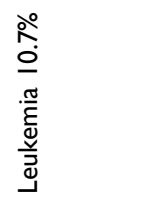 & 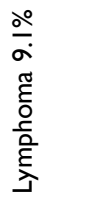 & 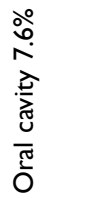 & 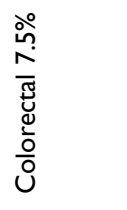 & 离 兰 & 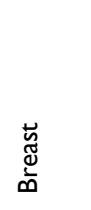 & 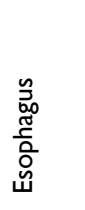 & 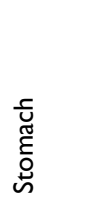 & $\stackrel{\infty}{{ }_{3}^{3}}$ \\
\hline 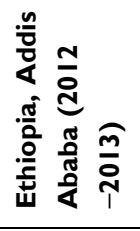 & 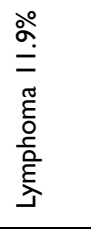 & 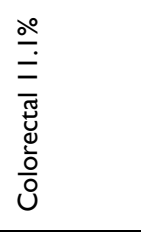 & 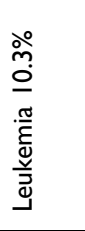 & 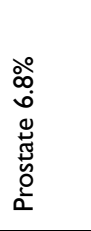 & 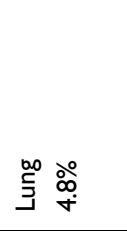 & 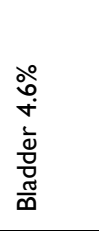 & 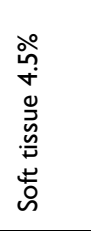 & 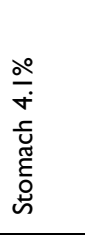 & 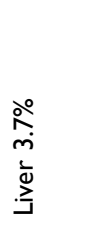 & 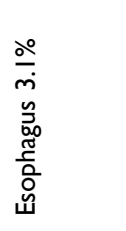 \\
\hline 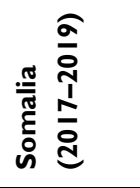 & 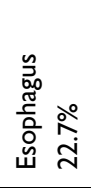 & 㐫 ㅇํํ & 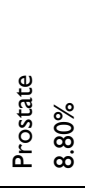 & 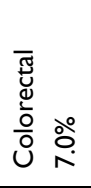 & 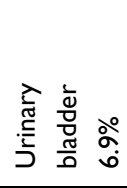 & 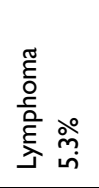 & 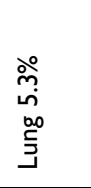 & 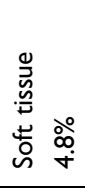 & 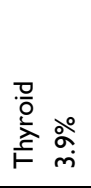 & 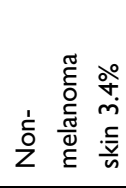 \\
\hline 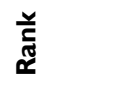 & - & $N$ & $m$ & $\sigma$ & Ln & 0 & $n$ & $\infty$ & $\sigma$ & 으 \\
\hline
\end{tabular}




\begin{tabular}{|c|c|c|c|c|c|c|c|c|c|c|}
\hline 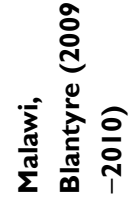 & 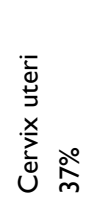 & 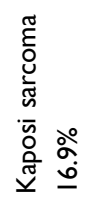 & 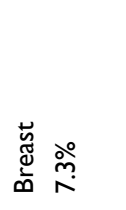 & 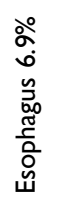 & 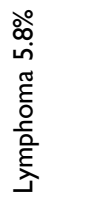 & 离 & 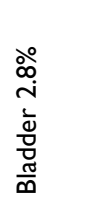 & 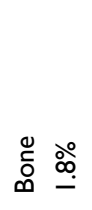 & 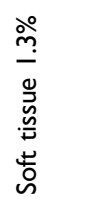 & 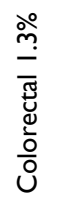 \\
\hline 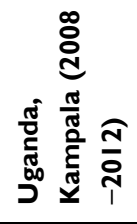 & 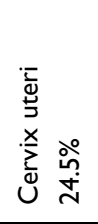 & 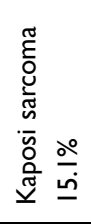 & 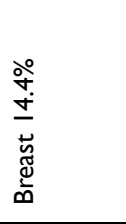 & 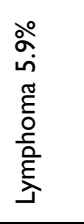 & 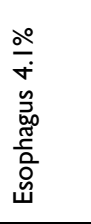 & 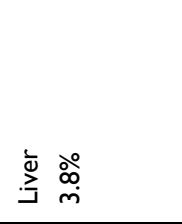 & 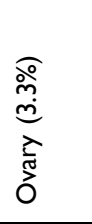 & 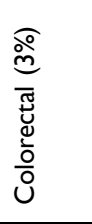 & 离 & 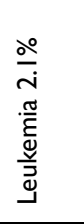 \\
\hline 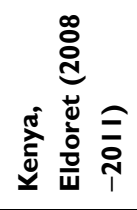 & 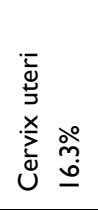 & 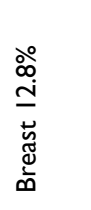 & 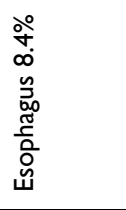 & 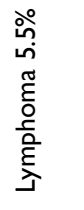 & 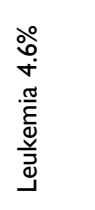 & 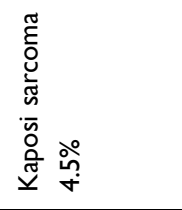 & 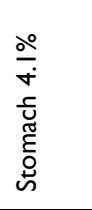 & 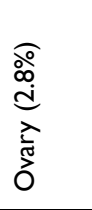 & 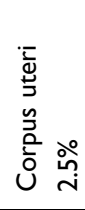 & 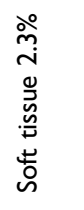 \\
\hline 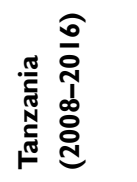 & 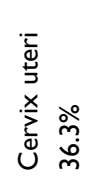 & 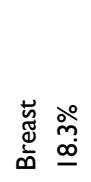 & 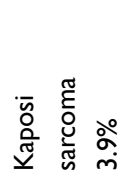 & 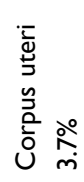 & 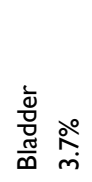 & 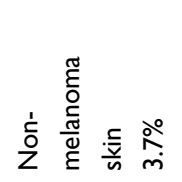 & 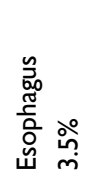 & ठิ & 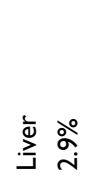 & 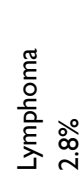 \\
\hline 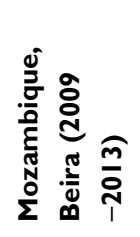 & 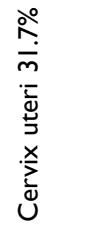 & 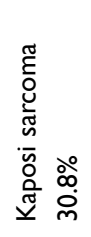 & 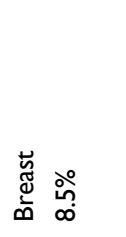 & 悹 iْ & 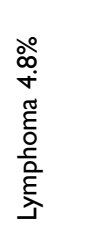 & 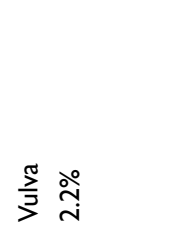 & 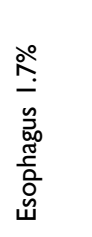 & 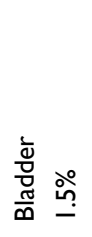 & $\stackrel{\bar{\Phi}}{\stackrel{亠}{\Xi}} \stackrel{\circ}{+}$ & 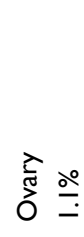 \\
\hline 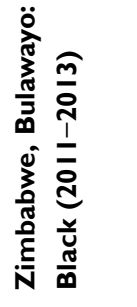 & 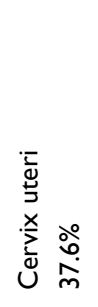 & 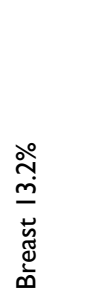 & 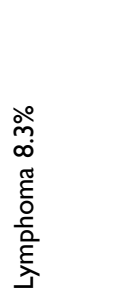 & 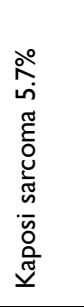 & 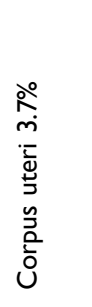 & 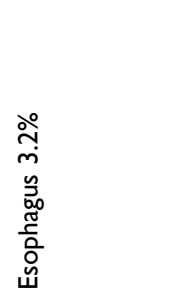 & 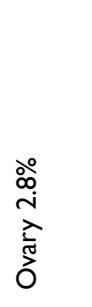 & 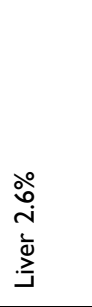 & 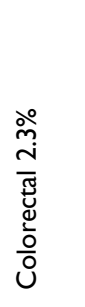 & 㫕 $\frac{\circ}{\mathrm{N}}$ \\
\hline 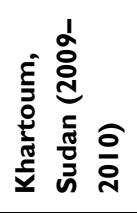 & 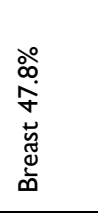 & $\begin{array}{l}\frac{\circ}{\sigma} \\
\frac{.0}{\tilde{E}} \\
\frac{\bar{\omega}}{\vec{\Xi}}\end{array}$ & 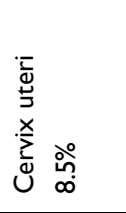 & 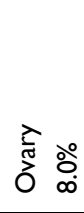 & 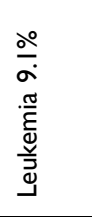 & 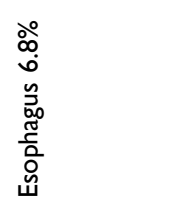 & 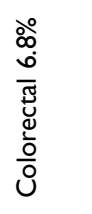 & 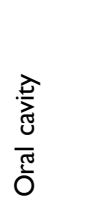 & 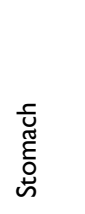 & $\stackrel{\infty}{\underbrace{3}}$ \\
\hline 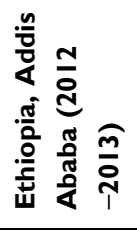 & 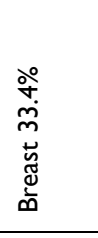 & 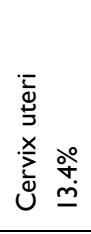 & 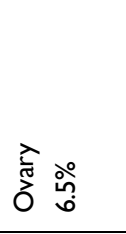 & 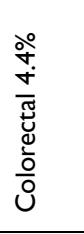 & 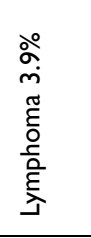 & 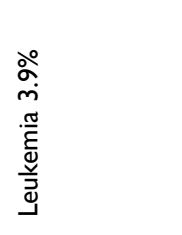 & $\begin{array}{l}\stackrel{\circ}{0} \\
\text { mं } \\
\stackrel{0}{0} \\
\stackrel{0}{\grave{\lambda}} \\
\text { F }\end{array}$ & 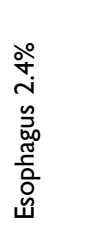 & 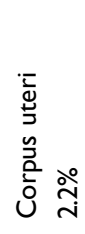 & 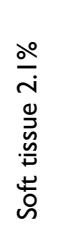 \\
\hline 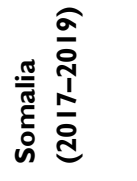 & 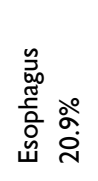 & 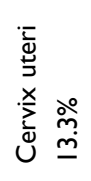 & 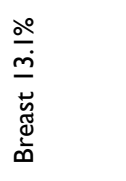 & 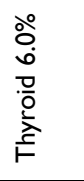 & 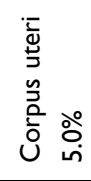 & 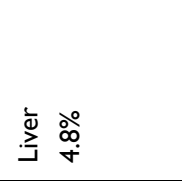 & 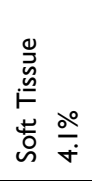 & 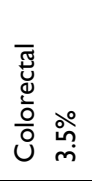 & 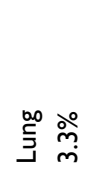 & ठ̀ \\
\hline 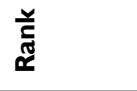 & - & $N$ & $m$ & $\sigma$ & in & 0 & $\wedge$ & $\infty$ & $a$ & 으 \\
\hline
\end{tabular}


Table 4 Type and Frequency of Cancers in Pediatric Cases

\begin{tabular}{|l|l|}
\hline Location/Type & n (\%) \\
\hline Lymphoma & $12(21.4)$ \\
Wilms' tumor & $9(16.1)$ \\
Colorectal & $8(14.3)$ \\
Nasopharynx & $6(10.7)$ \\
Brain & $4(7.1)$ \\
Tongue & $3(5.4)$ \\
Salivary gland & $2(3.6)$ \\
Eye & $2(3.6)$ \\
Bone & $2(3.6)$ \\
Peritoneal & $2(3.6)$ \\
Breast & $1(1.8)$ \\
Kidney & $1(1.8)$ \\
Lung & $1(1.8)$ \\
Ovary & $1(1.8)$ \\
Thyroid & $I(1.8)$ \\
Stomach & $I(1.8)$ \\
Total & $56(100)$ \\
\hline
\end{tabular}

context, our data indicating EC as the most common cancer in both genders reveals the importance of devising new screening programs for Somalia, different from the remainder of the world.

\section{Liver Cancer}

Liver cancer is estimated to be the sixth most frequently diagnosed cancer and the fourth leading cause of cancer deaths worldwide, with approximately 841,000 new cases and 782,000 deaths per year. In most regions, both incidence and mortality associated with liver cancer are two to three times higher among men. It is the most common cancer in 13 geographical countries, especially in North and West Africa. ${ }^{3}$ In the current study, liver cancer was determined as the sixth most common cancer in Somalia according to the overall ranking while it was the second most common cancer in men. The incidence of liver cancer was twice as high in men as in women. Primary liver cancer includes hepatocellular carcinoma (HCC) (75-85\% of cases) and intrahepatic cholangiocarcinoma (10-15\% of cases), and other rare types. Major risk factors for $\mathrm{HCC}$ are $\mathrm{HBV}$ or $\mathrm{HCV}$, aflatoxin-contaminated foodstuffs, heavy alcohol intake, obesity, smoking, and type 2 diabetes. $^{3,23}$ In Somalia, tobacco use is very low and alcohol consumption is prohibited. In our study, only $19.2 \%(n=19)$ of the cases had HBV $(n=17)$ or HCV $(n=2)$ infection. Only two of the patients had a history of type 2 diabetes. However, although the etiology of other cases is not precisely known, in recent years, it has been reported that foods contaminated with aflatoxin have increased the incidence of liver cancer, especially in East Africa. $^{24}$ Therefore, further research (case-control studies, cohort studies, etc.) should be conducted to reveal the relationship between aflatoxin and liver cancer in the region.

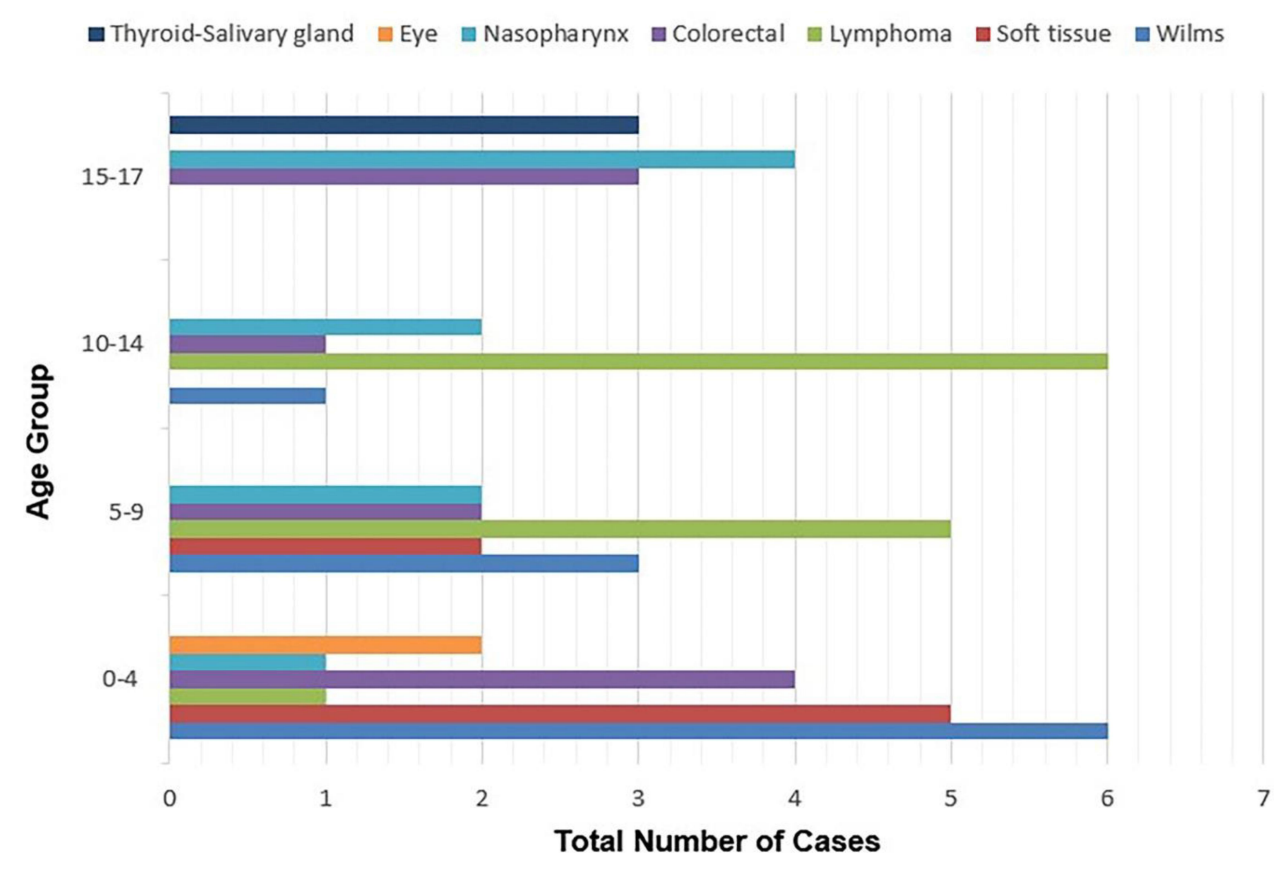

Figure 6 Distribution of the most common cancer types in pediatric cases. 


\section{Cervix Uteri Cancer}

Cervical cancer is the fourth most frequently diagnosed cancer (ASR of 13.1/100,000) and fourth leading cause of cancerrelated deaths in women, with 570,000 new cases $(6.6 \%$ of the global total) and 311,000 deaths $\left(7.5 \%\right.$ of the global total). ${ }^{3}$ The 2018 data show that cervical cancer ranks second in incidence and mortality in low-income countries (LICs) after breast cancer; however, it is the most frequently diagnosed cancer in 28 countries and the leading cause of cancer deaths in 42 countries, with the vast majority of cases being reported in SSA and Southeast Asia. ${ }^{3}$ According to WHO, the incidence of cervical cancer, which ranked second in Somalia after breast cancer in 2018 is reported to have an incidence of 24/ 100,000 and mortality of $21.6 / 100,000 .{ }^{25}$ In contrast, the data obtained from our study indicate that cervical cancer is more common than breast cancer and is the second most common cancer after EC. HPV is known to be responsible for almost all cervical cancer cases. Immunosuppression (especially HIV), smoking, parity, and oral contraceptive use are listed as other effective factors. In recent years, the incidence and mortality rates of cervical cancer have decreased in many populations around the world. This decrease has been associated with various factors, such as cervical screening (pap smear), improvements in genital hygiene, decreased parity, decreased sexually transmitted diseases, increased socioeconomic levels, and a reduced risk of permanent high-risk HPV infections. Studies conducted in the USA show that there are lower cervical screening rates among immigrant women (especially Somalian women) compared to the general USA population. ${ }^{6}$ Carroll et al. ${ }^{26}$ reported that Somalian women were not familiar with the tests and concepts used in cancer screening services. Studies have listed the reasons for not participating in cervical screening programs as not having sufficient information, feeling pain, fear or embarrassment, lack of trust in the healthcare system and doctors, and religious beliefs. Religion has an important place in Somalian society.

In studies on immigrants, most of the participants stated that they believed that prevention was not possible and if the disease was to develop, screening would not be helpful and would not change the outcome. ${ }^{6}$ Cervical cancer, which is seen as the most common cancer in many East African countries, was had second highest incidence after EC in our study (Table 3 ). The high rate of multiparity, poor genital hygiene, and insufficient development of screening programs in Somalia can be stated as factors that increase the incidence of the disease.

\section{Breast Cancer in Females}

Breast cancer is the most frequently diagnosed cancer in women worldwide (154 of 185 countries), increasing in frequency with 1.67 million new diagnoses in 2012 and 2.1 million new diagnoses in 2018. ${ }^{3}$ Although the incidence of breast cancer is lower in LICs, the mortality/incidence rate is higher. This can be attributed to various factors, such as limited financial and human resources for effective treatment, reduced benefit of treatment due to advanced presentation of patients. $^{27,28}$ The International Agency for Research on Cancer (IARC) data show that SSA is the most common cancer in women with 94,378 cases and 47,583 deaths reported in 2012 (compared to 93,225 cervical cancer cases). However, with the increasing incidence of cervical cancer in recent years, it is now seen to rank second in most SSA countries. ${ }^{28,29}$ In contrast, the data of our study show that breast cancer ranks third after cervical cancer in Somalia. Since most SSA countries do not have national cancer registries, the true cancer burden and incidence in SSA are not fully understood and probably underreported. ${ }^{28}$ It is considered that the data do not reflect the true incidence due to the lack of screening programs and the low rate of mammography screening in Somalia.

In a meta-analysis, the age of breast cancer cases in SSA at the time of diagnosis was reported to be below 45 years in $34 \%$ of the studies, $45-49$ years in $43 \%$, and over 50 in $19 \% .{ }^{30}$ In the current study, for breast cancer, which was the third most common cancer, the mean age at the time of diagnosis was determined as 44 years.

As in most SSA countries, the greatest challenge in Somalia is lack of awareness and knowledge. However, women in the region are at higher risk due to their inability to access high-quality healthcare, fear of stigma, and emotional trauma caused by breast cancer. Documented statistics are not a true reflection of the breast cancer prevalence of most countries, since these countries do not always have well-functioning national cancer registries. This situation is one of the most important problems in breast cancer management. Furthermore, lack of funding, poverty, inadequate health facilities, low staffing, ignorance, and neglect remain the biggest challenges faced in breast cancer management. In addition, effective cancer management requires radiological services and professionals, as well as oncologists and relevant health professionals that are limited in number in SSA countries.

In our study, there is a relatively high rate of male breast cancer 8 of 95 cases. This may reflect detection or 
perhaps avoidance of care due to cultural reasons, but a few similar studies support our data. ${ }^{31}$

\section{Pediatric Cancer Cases}

According to the data the Surveillance, Epidemiology, and End Results Program (SEER), although the most common tumors of childhood are leukemia and those of the central nervous system (CNS) across the world, the most frequently reported in SSA are Kaposi sarcoma, Burkitt lymphoma, retinoblastoma, and visible tumors, such as Wilms'. ${ }^{24}$ It is noteworthy that in Tanzania there were only few CNS (4.3\%) and leukemia $(0.6 \%)$ tumors among pediatric cases, constituting $17.5 \%$ of cancer cases for the period between 2006 and 2018. Similarly, in our study, the childhood tumors that constituted $5.1 \%$ of the cases were mostly lymphomas, Wilms' tumor, retinoblastomas, and tumors of the nasopharynx and thyroid gland (Table 4 and Figure 6). Little is known about pediatric cancer incidences in Africa. Similar to most African countries, the data of this study conducted in Somalia were obtained from hospitalized patient records and were solely based on the pathology findings of biopsy or surgical specimens. Many such cases are referred to an advanced center without a pathological diagnosis due to the lack of a pediatric oncology clinic. ${ }^{7}$

The most important limitation of this study is that it only included patients that presented to STRTEH, but it is the largest and most comprehensive examination facility in the country. In addition, there are a few other limitations; the exclusion of cases that do not have pathology confirmation could limit the incidence of cancer. The other limitation is that patients travel to other countries for diagnosis and treatment.

\section{Conclusion}

This is the first comprehensive study investigating the cancer epidemiology in the Somali population. Similar to another study of a tertiary care center within East Africa on pathologically-confirmed malignancies, EC was found to be the most frequently diagnosed cancer in both genders. These high rates in Somalia suggest that environmental factors and dietary habits may have an effect. To reduce the incidence of $\mathrm{EC}$ and prevent its development, the population of Somalia should be educated and effective planning should be undertaken. However, in the absence of a national cancer registry system in Somalia, it is difficult to understand the epidemiology of EC and other cancers and develop programs for cancer control and prevention. Since STRTEH is a referral hospital providing tertiary healthcare services in Somalia, the results obtained are very valuable and provide important information for cancer control and prevention in Somalia. This study is of great importance for the health system of the country since any prevention policy cannot be implemented without epidemiological studies and very comprehensive statistical analyses. However, it is also necessary to initiate the establishment of a regional cancer registry system in order to allow the monitoring of cancer trends and effectively plan cancer control.

\section{Abbreviations}

WHO, World Health Organization; USA, United States of America; STRTEH, Somalia Turkey Recep Tayyip Erdogan Education and Research Hospital; US, ultrasound; CT, computed tomography; ASR, agestandardized rate; EC, esophageal cancer; SCC, squamous cell carcinoma; HIV/AIDS, human immunodeficiency virus/acquired immune deficiency syndrome; HBV, hepatitis B virüs; HCV, hepatitis C virüs; SSA, Sub-Saharan Africa; HCC, hepatocellular carcinoma; LICs, low-income countries; IARC, International Agency for Research on Cancer; CNS, central nervous system.

\section{Ethics Approval and Consent to Participate}

The study was approved by Ethics Committee of Somalia Turkey Recep Tayyip Erdogan Education and Research Hospital and conducted in accordance with the Declaration of Helsinki. As this study is retrospective, the requirement for informed consent by the ethics committee was waived. All data on the patients was anonymized or maintained with confidentiality.

\section{Disclosure}

The authors report no conflicts of interest in this work.

\section{References}

1. Torre LA, Bray F, Siegel RL, Ferlay J, Lortet-Tieulent J, Jemal A. Global cancer statistics, 2012. CA Cancer J Clin. 2015;65(2):87-108. doi: $10.3322 /$ caac. 21262

2. Ferlay J, Soerjomataram I, Dikshit R, et al. Cancer incidence and mortality worldwide: sources, methods and major patterns in GLOBOCAN 2012. Int $J$ Cancer. 2015;136(5):E359-E386. doi:10.1002/ijc. 29210

3. Bray F, Ferlay J, Soerjomataram I, Siegel RL, Torre LA, Jemal A. Global cancer statistics 2018: GLOBOCAN estimates of incidence and mortality worldwide for 36 cancers in 185 countries. CA Cancer J Clin. 2018;68(6):394-424. doi:10.3322/caac.21492 
4. World Health Organization. Latest Global Cancer Data. Geneva: World Health Organization; 2018. https://www.who.int/cancer/ PRGlobocanFinal.pdf?ua=1. Accessed September 12, 2018.

5. Baş Y, Hassan HA, Bulur O, Ibrahim İA. Author 's Accepted Manuscript. 2017. doi:10.1053/j.seminoncol.2017.10.007

6. Ghebre RG, Sewali B, Osman S, et al. Cervical Cancer: barriers to Screening in the Somali Community in Minnesota. J Immigr Minor Heal. 2015;17(3):722-728. doi:10.1007/s10903-014-0080-1

7. Olson AC, Afyusisye F, Egger J, et al. Cancer incidence and treatment utilization patterns at a regional cancer center in Tanzania from 2008-2016: initial report of 2772 cases. Cancer Epidemiol. 2020;67 (June):101772. doi:10.1016/j.canep.2020.101772

8. Parkin DM, Bray F, Ferlay J, Jemal A. Cancer in Africa 2012. Cancer Epidemiol Biomarkers Prev. 2014;23(6):953-966. doi:10.1158/10559965.EPI-14-0281

9. Jedy-Agba EE, Curado MP, Oga E, et al. The role of hospital-based cancer registries in low and middle income countries-The Nigerian Case Study. Cancer Epidemiol. 2012;36(5):430-435. doi:10.1016/j. canep.2012.05.010

10. World Health Organization. Global Cancer Observatory; 2018. Available from: https://gco.iarc.fr/today/data-sources-methods. Accessed September 3, 2020.

11. World Health Organization. Global Cancer Observatory; 2018. Available from: https://gco.iarc.fr/today/online-analysistable?v= $2018 \& \operatorname{mode}=$ cancer $\&$ mode population $=$ countries \& population $=$ $900 \&$ populations $=903 \_900 \_706 \& \mathrm{key}=\mathrm{asr} \& \mathrm{sex}=0 \& \mathrm{cancer}=$ $39 \&$ type $=0 \&$ statistic $=5 \&$ prevalence $=0 \&$ population_group $=0 \&$ ages group $\% 255 \mathrm{~B} \% 255 \mathrm{D}=0$ \&ages_group $\% 255 \mathrm{~B} \% 255 \mathrm{D}=17$. Accessed September 3, 2020.

12. Asombang AW, Chishinga N, Nkhoma A, et al. Systematic review and meta-analysis of esophageal cancer in Africa: epidemiology, risk factors, management and outcomes. World J Gastroenterol. 2019;25 (31):4512-4533. doi:10.3748/wjg.v25.i31.4512

13. Kabat GC, Shivappa N, Hébert JR. Mentholated cigarettes and smoking-related cancers revisited: an ecologic examination. Regul Toxicol Pharmacol. 2012;63(1):132-139. doi:10.1016/j. yrtph.2012.03.002

14. Cheng ML, Zhang L, Borok M, et al. The incidence of oesophageal cancer in Eastern Africa: identification of a new geographic hot spot? Cancer Epidemiol. 2015;39(2):143-149. doi:10.1016/j.canep.2015.01.001

15. Persson EC, Shiels MS, Dawsey SM, Bhatia K, Anderson LA, Engels EA. RETRACTED: increased Risk of Stomach and Esophageal Malignancies in People With AIDS. Gastroenterology. 2012;143(4):943-950.e2. doi:10.1053/j.gastro.2012.07.013

16. Mbulaiteye SM, Katabira ET, Wabinga H, et al. Spectrum of cancers among HIV-infected persons in Africa: the Uganda AIDS-Cancer Registry Match Study. Int J Cancer. 2006;118(4):985-990. doi:10.1002/ ijc. 21443

17. Islami F, Poustchi H, Pourshams A, et al. A prospective study of tea drinking temperature and risk of esophageal squamous cell carcinoma. Int J Cancer. 2020;146(1):18-25. doi:10.1002/ijc.32220

18. Mwachiro MM, Parker RK, Pritchett NR, et al. Investigating tea temperature and content as risk factors for esophageal cancer in an endemic region of Western Kenya: validation of a questionnaire and analysis of polycyclic aromatic hydrocarbon content. Cancer Epidemiol. 2019;60:60-66. doi:10.1016/j.canep.2019.03.010

Cancer Management and Research

Publish your work in this journal

Cancer Management and Research is an international, peer-reviewed open access journal focusing on cancer research and the optimal use of preventative and integrated treatment interventions to achieve improved outcomes, enhanced survival and quality of life for the cancer patient.
19. Leon ME, Assefa M, Kassa E, et al. Qat use and esophageal cancer in Ethiopia: A pilot case-control study. PLoS One. 2017;12(6):1-17. doi:10.1371/journal.pone. 0178911

20. Hamashima C. Update version of the Japanese Guidelines for Gastric Cancer Screening. Jpn J Clin Oncol. 2018;48(7):673-683. doi:10.1093/jjco/hyy077

21. Autier P, Boniol M. Mammography screening: A major issue in medicine. Eur J Cancer. 2018;90:34-62. doi:10.1016/j.ejca.2017.11.002

22. Sachan P, Singh M, Patel M, Sachan RA. Study on Cervical Cancer Screening Using Pap Smear Test and Clinical Correlation. AsiaPacific J Oncol Nurs. 2018;5(3):337. doi:10.4103/apjon.apjon_15_18

23. Marengo A, Rosso C, Bugianesi E. Liver Cancer: connections with Obesity, Fatty Liver, and Cirrhosis. Annu Rev Med. 2016;67 (1):103-117. doi:10.1146/annurev-med-090514-013832

24. Stefan DC. Patterns of Distribution of Childhood Cancer in Africa. J Trop Pediatr. 2015;61(3):165-173. doi:10.1093/tropej/fmv005

25. World Health Organization. Global Cancer Observatory; 2018. https:// gco.iarc.fr/today/online-analysis-multi-bars. Accessed September 3, 2020.

26. Carroll J, Epstein R, Fiscella K, Volpe E, Diaz K, Omar S. Knowledge and Beliefs About Health Promotion and Preventive Health Care Among Somali Women in the United States. Health Care Women Int. 2007;28 (4):360-380. doi:10.1080/07399330601179935

27. Cumber SN, Nchanji KN, Tsoka-Gwegweni JM. Breast cancer among women in sub-Saharan Africa: prevalence and a situational analysis. South African J Gynaecol Oncol. 2017;9(2):35-37. doi:10.1080/20742835.2017.1391467

28. Black E, Richmond R. Improving early detection of breast cancer in sub-Saharan Africa: why mammography may not be the way forward. Global Health. 2019;15(1):1-11. doi:10.1186/s12992-018-0446-6

29. Ferlay J, Colombet M, Soerjomataram I, et al. Estimating the global cancer incidence and mortality in 2018: GLOBOCAN sources and methods. Int J Cancer. 2019;144(8):1941-1953. doi:10.1002/ijc.31937

30. Jedy-Agba E, McCormack V, Adebamowo C, dos-Santos-Silva I. Stage at diagnosis of breast cancer in sub-Saharan Africa: a systematic review and meta-analysis. Lancet Glob Heal. 2016;4 (12):e923-e935. doi:10.1016/S2214-109X(16)30259-5

31. Ndom P, Um G, Bell EMD, Eloundou A, Hossain NM, Huo D. A meta-analysis of male breast cancer in Africa. The Breast. 2012;21 (3):237-241. doi:10.1016/j.breast.2012.01.004

32. Parkin D, Ferlay J, Jemal A, et al. Cancer in Africa Cancer in SubSaharan Africa. Vol. 167. IARC Scientific Publication 167; 2018.

33. Saeed IE, Weng HY, Mohamed KH, Mohammed SI. Cancer incidence in Khartoum, Sudan: first results from the Cancer Registry, 2009-2010. Cancer Med. 2014;3(4):1075-1084. doi:10.1002/cam4.254

34. Pan D, Su M, Zhang T, et al. A Distinct Epidemiologic Pattern of Precancerous Lesions of Esophageal Squamous Cell Carcinoma in a High-risk Area of Huai'an, Jiangsu Province, China. Cancer Prev Res. 2019;12 (7):449-462. doi:10.1158/1940-6207.CAPR-18-0462
The manuscript management system is completely online and includes a very quick and fair peer-review system, which is all easy to use. Visit http://www.dovepress.com/testimonials.php to read real quotes from published authors. 